\title{
Editorial
}

\section{The challenges of branding}

Since this Editorial coincides with the first issues of The Journal of Brand Management, it will delineate what appears to be some of the biggest problems facing brand managers. It would be gratifying to receive papers on these topics and to witness a shift of emphasis of research beyond traditional consumer studies.

The majority of marketing theories and textbooks have been conceived for times of economic strength. As MBA students, brand managers used to read case studies where market growth was assured. The normal brand decision was to ask for a premium price and demand was always considered to be present. Nowadays, Europe is in the grip of a recession, where consumer demand has shrunk and turned towards cheap, unbranded products. In this economic climate, yesterday's speeches on the financial value of brands seem fragile. Brand financial equity is a measure of the incremental revenue one may derive from a brand. If consumers are no longer prepared to pay more for brands, what should be done to maintain this value? Should one wait for better days? Should one stick to the market share by decreasing its shelf price, as Marlboro did?

In many cases, one wonders if consumers will return to brands after having purchased unbranded spaghetti, unknown brands or own label for a lengthy period. It is my feeling that the last economic boom was a practical alibi to launch a number of weak brands and also a time which enabled others to survive. The present hard times will prune the market. It is time for corporations to drop all ailing or pseudo-brands, and to concentrate on those few which are able to justify their price difference on objective values.

The current challenge arises from the price differential of new active entrants. That difference, once considered reasonable, has become enormous in the eyes of consumers, who compare the gap between shelf prices of well-known brands and those of own label or unknown brands used as first price products. Technology has advanced: low price no longer means poor quality in all product categories. Consumers may well be satisfied with a lower level of taste or performance. In the price/quality trade-off, they prefer price savings to high quality. It is not sufficient for brands to just state or depict their difference, they must actively sell it in order to make it justify the higher price.

The majority of past research on brands has been based on consumer micro-psychology. For instance, brand extension studies focused on consumers' reactions to a Heineken popcorn. Nowadays, the first group to decide about the future of an extension is the distributor, not the consumer. It is time for brand management to take the trade into account. Since brands have less shelf space because of the presence of distributor's own labels, the line extension will rarely obtain an empty space, but will be placed within the brand's existing facings. One should therefore speak of line substitution instead of extension. The distributor will also check if the new product turnover is as good as, or inferior to the former product on shelf. If the latter is the case, then the extension will soon be delisted. It is the distributors who have become the major gatekeepers of the market, and therefore 
modern brand management must incorporate their reactions.

Finally, many major corporations have so far considered it sinful to produce for own labels. Since own labels are here to stay, in the present economic situation, can these axiomatic stances remain? There are very few brands desperately needed by distributors, such as Coca-Cola and some product categories of Nestlé. The vast majority of brands are not in such a powerful situation. Instead of deploring the rise of own labels, isn't it time to see this as an opportunity to gain a competitive advantage on other manufacturers. Competitive brand management should also involve unbranded management!

Jean-Noël Kapferer Editorial Board 